\title{
ABNORMAL INFLUENCE OF IONS ON SHOCK-INDUCED POLARIZATION IN BINARY ELECTROLYTES
}

\author{
B. Martuzans, Yu. Skryl \\ Institute of Mathematics and Computer Science, University of Latvia, \\ 29 Rainis Blvd., Rīga, LV-1459, LATVIA
}

The study is aimed at modeling the shock-induced polarization of liquid superdiluted binary (KF) electrolytes at low $\left(<10^{-4}\right.$ mole fraction) concentration of $\mathrm{K}^{+}$ and $\mathrm{F}^{-}$ions (i.e. not making direct contribution to the polarization current). It is supposed that at such a small concentration of electrolyte only the dipole polarization of water occurs, while the indirect influence of ions is expressed in its reduced conductivity in the compressed region at increasing concentration of the dissolved ions. In the authors' opinion, this influence is connected with suppression of the transition of water into high-conductivity phase by the ions of electrolyte.

\section{INTRODUCTION}

Appearance of electric conductivity and its increase behind a shock wave front is a well-known phenomenon in the shock waves physics [1-3]. This phenomenon may be connected both with ionization of atoms in gases and plasma behind this front $[4,5]$ and with a band gap narrowing in solid insulators and semiconductors during a shock compression [6,7]. At high enough pressure in such solids as selenium and silicon a metallic conductivity may be created in the shock compression region due to the insulator-metal phase transition as a result of the band gap closure $[8,9]$. An increase in the conductivity behind the shock wave front is also observed for liquid insulators, e.g. distilled water [10]. According to [11], this could be explained by increasing proton conductivity [11], while the authors of [12] suggest that there is dissociation of water under pressure. However, the mechanism of the mentioned increase is still unclear.

Experimental measurements of the conductivity behind the wave front are rather complex and not exact enough, consisting in measuring directly the material resistance [7,8]. At the same time, the authors of work [13] show that it is possible to explain this high conductivity based on the shock-induced polarization data. The initial peak on the current-time characteristics indicates a strong reduction in the resistance of material behind the shock wave front, which is always absent when the shocked sample retains the insulator properties. The model of shock-induced polarization with appearance of conductivity in the material offered in [13] allows for adequate explanation of polarizing currents in Plexiglas close to the phase transition observed by Hauver [14]. In this case, in our opinion, a high conductivity is to appear.

In the present work, an attempt is made to analyze the insulation properties of water based on the experimental polarization data relating to water solution of KF-electrolyte $[15,16]$ in the region of concentrations too low to give a direct contribution to the conductivity. 
As follows from experiments with shocked KF-electrolyte [16], the initial peak on the current-time characteristics is always observed at the electrolyte concentrations below some critical concentration $C_{c}$, which disappears at higher concentrations. Such behavior of polarization current cannot be explained by ionic contribution to conductivity, since in this case the concentration dependence would be opposite. Moreover, direct calculations of the polarization current of KFelectrolyte [17] show that the contribution of ions to the conductivity of the electrolyte at concentrations below $C_{\mathrm{c}}$ is infinitely small. Nevertheless, there is ionic influence on the shape of polarization curves at low concentrations, which is of a more refined character. To explain this phenomenon, in the present work some assumptions are proposed. First, it is supposed that the dipole polarization of water dominates at ionic concentrations below $C_{\mathrm{c}}$. Second, the high conductivity observed is created behind the shock front as a result of structural modification of the water. Third, this high conductivity is created at critical pressure $P_{\mathrm{c}}$ whose values can be varied in the model for better comparison with the experimental polarization currents. The analysis of the experimental data shows that the offered model describes them well enough at the mentioned small concentration of KFelectrolyte. Besides, the analysis gives a direct-proportional dependence of critical pressure $P_{c}$ on the concentration of electrolyte. Such dependence could be explained by suppressing the transition of water to the high conductivity phase by electrolytic ions.

\section{POLARIZATION MODEL}

We will consider a polarization model for water solution of electrolyte taking into account the formation of a high conductivity zone behind the front of a shock wave. The basic concepts of this model were developed in [13]. The model satisfactorily describe polarization curves in Plexiglas at the pressure close to critical when there occurs a shock-induced phase transition [14], which is connected, in our opinion, with increased conductivity [13]. As before, in the present work it is supposed that the conductivity behind the front of a shock wave is so high that it is possible to extend the area of the ohmic contact deep into the dielectric sample in the direction of the shock wave front propagation. As a result, we could formulate the polarization problem for a dielectric sample with a mobile boundary moving together with the wave front. At the critical pressure $P_{\mathrm{c}}$ a high conductivity in the sample arises, i.e. actually a new metal-dielectric junction forms within the area of the shock wave front. Therefore the front structure is of utmost importance in the considered model - it does not work if the front width is equal to zero. In this sense the offered model strongly differs from that proposed by Zeldovich [18], in which the shock wave is considered classically, i.e. with the front width equal to zero, and is more similar to a modified Allison's model [19] into which mobile boundaries of the sample are introduced.

Using the methods of work [13], the problem of polarization in dielectrics can be described mathematically by the following set of differential equations:

$$
\frac{\partial}{\partial x}\left(\varepsilon \varepsilon_{0} \frac{\partial \varphi(x, t)}{\partial x}\right)=-q(x, t) ;
$$




$$
q(x, t)=-\frac{\partial P(x, t)}{\partial x}-\tau \frac{\partial q(x, t)}{\partial t},
$$

where $\varphi$ is the potential; $q$ is the density of space charge; $\varepsilon, \varepsilon_{0}$ are the dielectric constants, $P$ is the polazation, $\tau$ is the relaxation time of the polarization charge. Potential $\varphi$ is determined from Eqs. (1)-(2) in the entire sample by solving the boundary problem with zeros at the ends of the sample, which reflects the fact that the electrodes in real measurements of the shock-induced polarization are grounded.

The bias current $j(x, t)$ is defined from the derivative of electric field $E(x, t)$ with respect to time, i.e.

$$
\begin{aligned}
& E(x, t)=-\frac{\partial \varphi(x, t)}{\partial x} ; \\
& j(x, t)=\varepsilon \varepsilon_{0} \frac{\partial E(x, t)}{\partial t} .
\end{aligned}
$$

The bias current for the dielectric (water) should have a constant value in the whole sample except for the place where the front of the shock wave is located. The problem is completely defined with exact definition of the polarization law. For polarization of water the full model given in [20] could be used, which considers in detail configurations of a water molecule. However, this model is rather complicated, and for our present consideration is not very important; here a simpler law of polarization is preferred, which is more evident, preserving at the same time all basic properties of the mentioned polarization model:

$$
P(x, t)=-\alpha p_{0} l_{0} N \frac{\partial \mu(x, t)}{\partial x},
$$

where $\mu=1-\rho_{0} / \rho$ is the degree of material compression by the shock wave, $\rho$ is the current density, and $\rho_{0}$ is the initial density of the material. The polarization value $P$ also depends upon the concentration of dipoles and dipole moment $p_{0}$, similarly to the classical case of orientation polarization [21]. The value $l_{0}$, introduced based on the dimension analysis, corresponds to the molecular size of a dipole. Coefficient $\alpha$ will be used in our model for calibration and comparison of the results with experiment.

An advantage of the given model is the opportunity to directly connect polarization $P(x, t)$ with the shock wave parameters. For example, it is possible to present the degree of compression $\mu(x, t)$ in the form of a running wave:

$$
\mu(x, t)=\frac{\mu_{1}}{1+\exp \left(\frac{4}{H}\left(x-\left(D-v_{1}\right) t\right)\right)},
$$

where $\mu_{1}=1-\rho_{0} / \rho_{1}, \rho_{1}$ is the density maximum of the compressed material behind the shock wave front; $D, v_{1}$ are the shock and the maximum mass velocities; $H$ is the wave front width. 
Function (6) models a compression step smeared over width $H$. It is shown that Eq. (5), together with Eq. (6), provides evidence that the shock front generates polarization. Indeed, a non-zero polarization appears within the shock front only at its being zero everywhere else.

The values of $\mu_{1}, v_{1}$ and $D$ can be defined from Hugoniot's curve for water, while the wave front width - as in [17, 22]:

$$
H=\frac{16 \eta}{\gamma_{0} D \rho_{0} \mu_{1} W},
$$

where $\gamma_{0}$ is the Grüneisen coefficient, $\eta$ is the volume viscosity, $W$ is a function depending on the material's parameters and the shock wave velocity; in our calculations, the value $W=3$ was assumed for water at pressures from 5 to $15 \mathrm{GPa}$.

\section{ION SUPPRESSION OF THE SHOCK-IINDUCED CONDUCTIVITY}

In the first approximation we will assume that there is so high conductivity behind the shock front that an ohmic contact is formed right behind the front. Unlike the case where a dielectric was placed on both sides of the shock front and the ohmic contacts were fixed at the boundaries of the sample, one of the contacts will be moving along with the shock front if the conductivity is high. The estimated conductivity behind the front is comparable with the conductivity (equal to or higher than that) in germanium semiconductor $\left(\sim 0.023 \mathrm{Ohm}^{-1} \mathrm{~cm}^{-1}\right)$, which guarantees that the time of Maxwell's relaxation (i.e. the time for the ohmic contact to be fully set up) is at least by an order of magnitude smaller than the time of the shock wave propagating through the material.

Typical distributions of the electric parameters along the shocked sample the potential $\varphi(x, t)$ and the electric field $E(x, t)$ - in the presented model of shockinduced polarization with high conductivity and without it (i.e. classical) behind the shock wave front are schematically shown in Fig.1.a, $b$. The shock wave moving from left to right is shown at the time moment when the wave front has completely entered the sample. The wave front generates some nonzero polarization (presented in the same picture as the density of polarization charges $q(x, t)$ ).
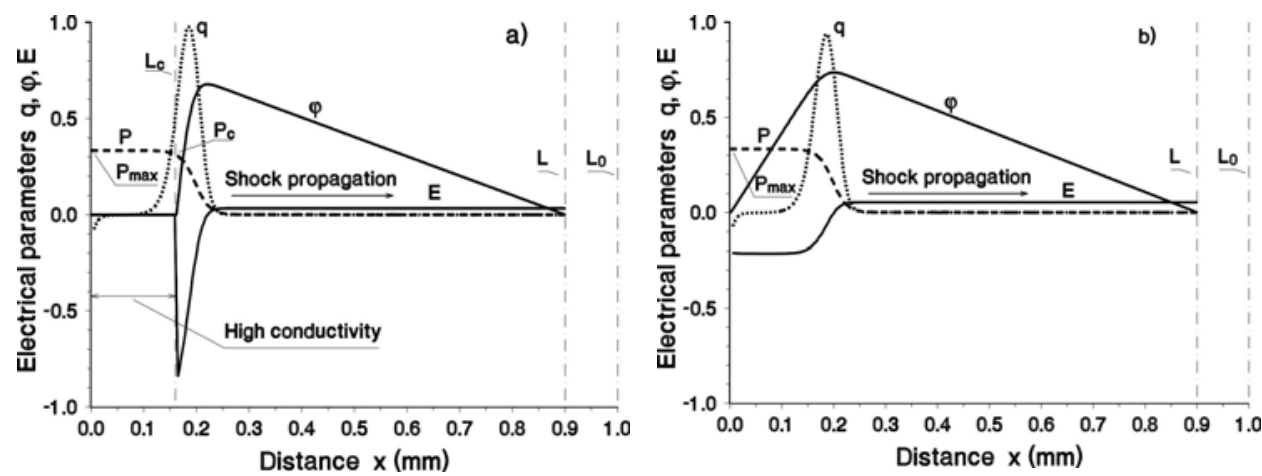

Fig. 1. Typical distributions (dimensionless) of the potential and the electric field (solid lines) in a shocked sample with $(a)$ and without $(b)$ high conductivity behind the wave shock front. The time moment is shown for the front that fully entered the sample (dashed line). The polarization charge created by the wave front is depicted by a dotted line. 
The high-conductivity area in the sample forms as a result of its compression by the shock wave in the region with pressure above $P_{\mathrm{c}}$, i.e. from the line of the left ohmic contact, $x=0$, up to the line $L_{\mathrm{c}}$. Actually, on line $L_{\mathrm{c}}$ the point of zero potential is located, which is used as a boundary condition for the Poisson equation (see Fig. 1a). Both the potential and the electric field in the region of high conductivity are equal to zero.

In Fig. 2, a typical shape of the time dependence of polarization current (broken lines) is presented for the case of formation of a high-conductivity area behind the shock wave. The polarization current is calculated as a bias current (see Eq. 4) at the point in the vicinity of the right ohmic contact (line $L$ ). For comparison, the polarization current calculated without formation of high conductivity is shown by a solid line. As is seen, the peak on the current-time characteristic corresponds to the appearance of conductivity behind the shock wave front - after its initial monotone increase the current sharply falls and then starts increasing again. Despite the current's falling at the time of conductivity formation practically to zero, afterwards it rises fast and can significantly exceed the current in a material retaining the dielectric properties.

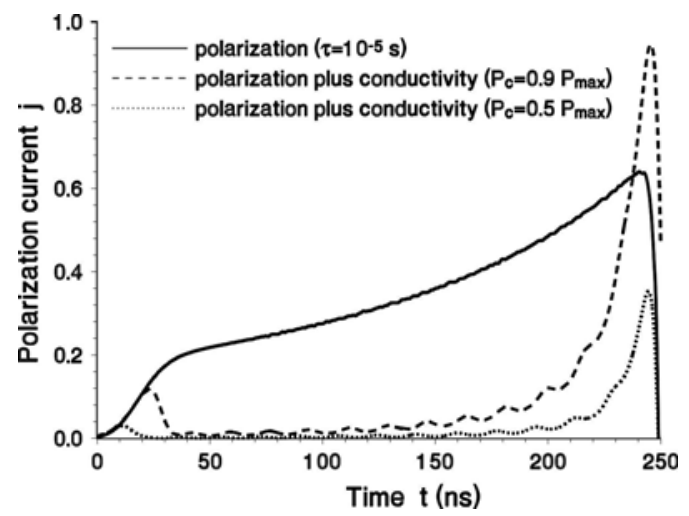

Fig. 2. Typical current-time characterictics (dimensionless) obtained from time dependences of the electric field with (broken lines) and without (solid line) shock-induced high conductivity behind the wave shock front.

The relaxation time for polarization process is $\tau=10^{-6} \mathrm{~s}$.

The point of critical pressure $P_{c}$ is usually located in the front region of a shock wave (not always close to the front edge) at the critical pressure approaching the shock wave amplitude $P_{\max }$ as in the case illustrated by Fig. 1. Figure 2 shows the current-time characteristic when the critical pressure is equal to half the shock wave amplitude, i.e. when $P_{\mathrm{c}}$ is located precisely amidst the front (a dotted line). The height of the initial peak decreases more than twice while its width increases only slightly. The second peak (much higher than the first one) forms during the time when the shock wave is leaving the sample and also considerably decreases but without significant change in the width. The first peak can most likely disappear absolutely if $P_{\mathrm{c}}$ is small enough. This means that the polarization charge in the shock wave front will be considerably neutralized by the high conductivity created at low critical pressure.

All types of curves shown in Fig. 2 are obtained experimentally at measuring polarization currents in KF-electrolyte $[15,16]$. From the data obtained it could 
also be is seen what curve corresponds only to the dipole polarization of water (see Fig. $4 e$ in [16]) and what - to the appearance of conductivity behind the shock wave front (see Fig. 4 a), b) and c) in [16]). Moreover, this conductivity appears not at increase in the concentration of the electrolyte as could naturally be expected, but, vice versa, at its decrease (see also Fig. 5 in [16]). More detailed analysis based on the polarization data the mentioned reference confirms this dependence.

Figure 3 displays the dipole polarization of water when the electric conductivity arises at the critical pressures smaller than the amplitude of the shock wave equal to $7 \mathrm{GPa}$. A close equivalence between the theoretical and the experimental data for polarization currents is obtained for the critical pressures of 6.5 GPa, 4.8 GPa and $3.5 \mathrm{GPa}\left(X=2 \cdot 10^{-6} ; X=2 \cdot 10^{-7}\right.$ and pure water [16]). A common feature of all the curves is existence of the initial peak at the very beginning of the graph, which becomes less pronounced for lower concentration values. The current at the time moment when the front is leaving the sample increases significantly - much steeper than that for the case of non-existent conductivity behind the shock front (compare with Fig. 2). This can be interpreted based on the analogy with a capacitor whose plates are moving towards each other with the speed of shock wave. Indeed, the potential at the wave front is constant when the conductivity arises, and the polarization current can be calculated as the bias current of the capacitor.
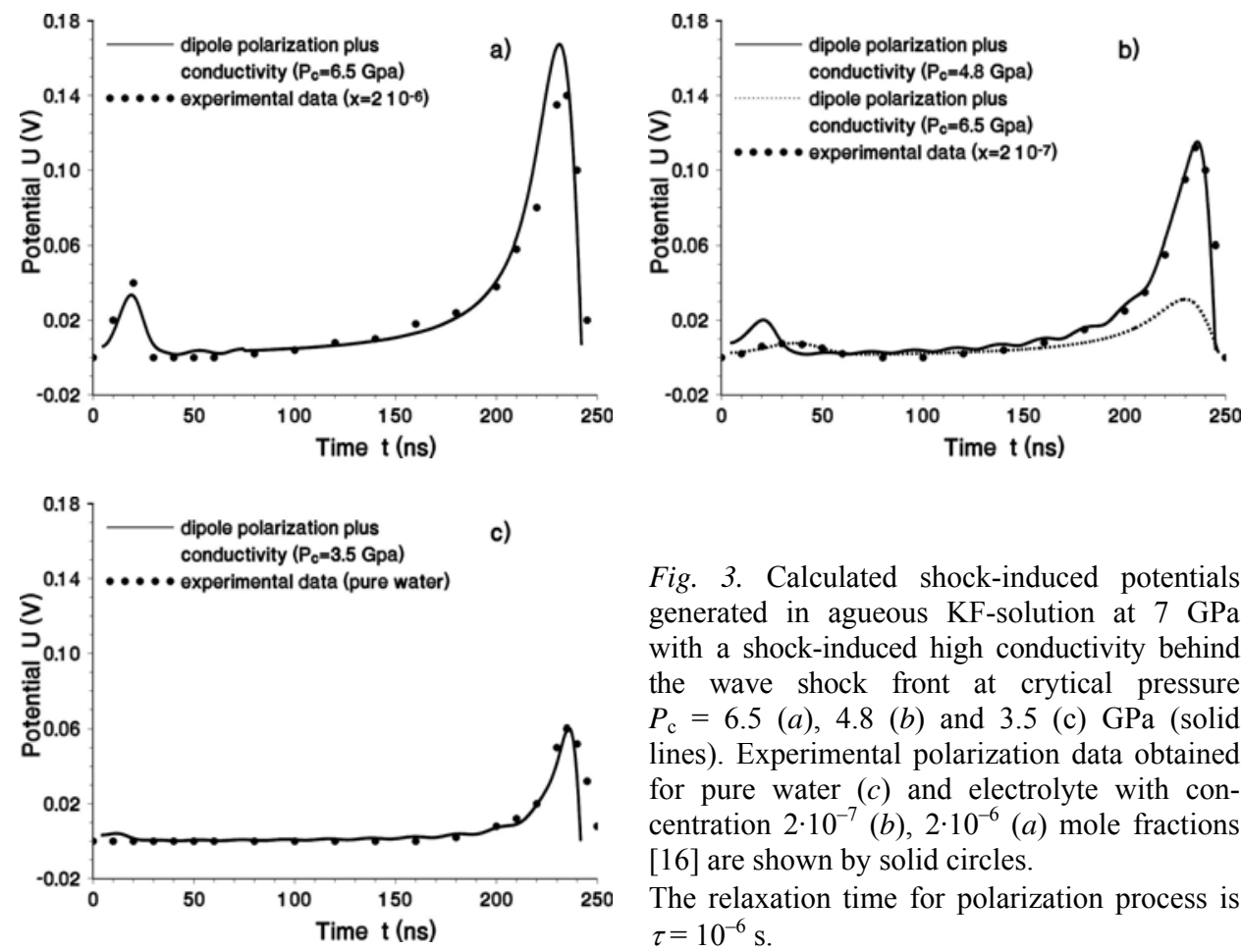

Fig. 3. Calculated shock-induced potentials generated in agueous KF-solution at $7 \mathrm{GPa}$ with a shock-induced high conductivity behind the wave shock front at crytical pressure $P_{\mathrm{c}}=6.5(a), 4.8(b)$ and 3.5 (c) GPa (solid lines). Experimental polarization data obtained for pure water $(c)$ and electrolyte with concentration $2 \cdot 10^{-7}(b), 2 \cdot 10^{-6}(a)$ mole fractions [16] are shown by solid circles.

The relaxation time for polarization process is $\tau=10^{-6} \mathrm{~s}$.

As seen in Fig. 3, the calculated polarization curves are in a good agreement with experimental measurements for different electrolyte concentrations. All the curves are obtained from a single function with fixed parameters $(\alpha=1200$ and 
$\eta=200$ Poise, $p_{0}=1$ Debay, $l_{0}=1 \mathrm{~A}$ and $N=0.1 \cdot N_{\mathrm{A}}$, where $N_{\mathrm{A}}$ is Avogadro's number) except for the plot for $X=2 \cdot 10^{-7}(\alpha=240$ and $\eta=600$ Poise at $6.5 \mathrm{GPa}$ only), which indicates that the dynamics of the potential exhibits nontrivial aspect of the critical pressure changes during the shock wave's moving through the sample (see Fig. 3b). While examining the relationship between concentrations with the associated critical pressures in our calculations, one can conclude that the increase in the electrolyte concentration results in a growth in the critical pressure attributed to the conductivity appearance. In a particular case of a high enough concentration, the critical pressure of the shock-induced conductivity may happen to be higher than the maximal pressure behind the front. This is perfectly illustrated in Fig. 5 of [16], where the polarization currents obtained at a concentration of $2 \cdot 10^{-4}$ mole fraction coincide with the classic polarization currents of dielectric material [19].

Such behavior favors the view that, most likely, the increased concentration of ions in the electrolyte solution suppresses the formation of shock-induced conductivity, which may imply that the ions play the role of a polluting impurity. At the same time, such strong influence of small concentration of electrolyte on the critical pressure indicates that this process is highly sensitive to pollutions.

\section{CONCLUSION}

A polarization model of water with high conductivity behind the shock wave front has been used to explain the experimental polarization data for superdiluted aqueous KF-solution. It is supposed that the high conductivity of structurally modified water may arise immediately at the values of pressure behind the shock wave front exceeding the critical level $\left(P_{\mathrm{c}}\right)$. These values must not exceed the maximal pressure in the shock wave and can be varied for the best comparison with the experimental polarization data. As a result of the comparison, a direct-proportional dependence of critical pressure $P_{\mathrm{c}}$ on the concentration of KF-electrolyte is obtained, which may be explained by suppression of the high-conductivity modification of water by $\mathrm{K}^{+}$and $\mathrm{F}^{-}$ions.

\section{REFERENCES}

1. Brish, A.A., Tarasov, M.S., \& Tsukerman, V.A. (1960). JETF, 38, 22.

2. Pavlovskij, M.N. (1967). FTT, 9 (11), 3192.

3. Nabatov, S.S., Dremin, A.N., Postnov, V.I., \& Jakushev, V.V. (1979). Pis'ma JETF, 29 (7), 407.

4. Biberman, L.N., Mnacakanjan, A.H., \& Jakubov, I.T (1970). Usp. Fiz. Nauk, 102, 431-462.

5. Postnikov, B.V., \& Jakovlev, V.I. (2002). Pis'ma JTF, 28, 82-89.

6. Kuklja, M.M., \& Kunz, A.B. (2000). J. Appl. Phys., 87, 2215.

7. Coleburn, N.L., Forbes, J.W., \& Jones, H.D. (1972). J. Appl. Phys., 43, 5007.

8. Gilev, S.D. (2006). JTF, 76, 41.

9. Gilev, S.D., \& Trubachev, A.M. (2004). J. Phys.: Condens. Matter., 16, 8139.

10. Brish, A.A., Tarasov, M.S., \& Cukerman, V.A. (1960). JETF, 33, 22.

11. Chau, R., Mitchell, A.C., Minich, R.W., \& Nellis W.J. (2001). J. Chem. Phys., 114, 1361.

12. Cavazzoni, C., Chiarotti, C.L., Scandolo, S., Tosatti, E., Bernasioni, M., \& Parrinello M. (1999). Science, 283, 44. 
13. Martuzans, B., \& Skryl, Yu. (2007). Numerical simulation of the shock-induced polarization in dielectric materials. Latv. J. Phys. Tech. Sci., 5, 41-52.

14. Hauver, G.E. (1965). J. Appl. Phys., 36, 2113.

15. Hironaka, Y., Nicol, F.M., \& Kondo, K. (1998). Shock Compression of Condensed Matter. In APS conference. (p.773).

16. Ogura, T., Hironaka Y., Nicol, F.M., Nakamura K.G., \& Kondo K. (2001). Jpn. J. Appl. Phys., 40, 2378.

17. Martuzans, B., \& Skryl, Yu. (2007). Numerical simulation of ionic transfer in shocked electrolytes. Latv. J. Phys. Tech. Sci., 6, 37-46.

18. Zeldovich, Ya.B. (1967). JETP, 53, 237.

19. Allison, F.E. (1965). J. Appl. Phys., 36, 2111.

20. Skryl, Yu., Belak, A.A., \& Kuklja, M.M. (2007). Shock-induced polarization in distilled water. Phys. Rev. B, 76, 064107.

21. Kittel, C. (2004). Introduction to Solid State Physics. New York: John Wiley \& Sons

\section{ANOMĀLĀ JONU IETEKME UZ TRIECIENA IZRAISĪTO POLARIZĀCIJU BINĀRAJOS ELEKTROLĪTOS}

B. Martuzāns, J. Skrils

\section{Kopsavilkums}

Šis pētījums ir veltīts trieciena izraisītās polarizācijas modelēšanai škidros stipri atšķaidītos bināros (KF) elektrolītos ar zemu $\left(<10^{-4}\right) \mathrm{K}^{+}$un $\mathrm{F}^{-}$jonu molāro koncentrāciju, kuriem nav tiešas ietekmes uz polarizācijas strāvu. Tiek pieņemts, ka pie tik zemām elektrolīta koncentrācijas vērtībām notiek ūdens dipolu polarizācija un ka joni netieši ietekmē vadāmības samazināšanos un šķīduma jonu koncentrācijas pieaugumu spiedienam pakḷautā apgabalā. Autori secina, ka šî ietekme ir saistīta ar trieciena izraisītās vadāmības samazināšanos, pateicoties jonu piemaisījumam.

12.02.2008. 